\title{
Making cardiac surgery feasible in African countries: Experience from Namibia, Uganda, and Zambia
}

Jessica Forcillo, MD, MSc, MPH, FRCSC, ${ }^{a}$ David A. Watkins, MD, MPH,${ }^{\mathrm{b}}$ Andre Brooks, FCS,, $\mathrm{d}$ Christopher Hugo-Hamman, FCP, ${ }^{\mathrm{e}}$ Laston Chikoya, MD, ${ }_{\mathrm{f}}^{\mathrm{f}}$ Michael Oketcho, MMed, ${ }^{\mathrm{g}}$ Vinod H. Thourani, MD, ${ }^{\mathrm{h}}$ and Liesl Zühlke, MBCHB, MPH, PhD, ${ }^{\text {b,i }}$ on behalf of contributors from Namibia, Zambia, and Uganda

\section{ABSTRACT}

Objectives: Few African countries have the resources to provide optimal cardiac surgery care. We explored needs at cardiac surgery centers in Namibia, Zambia, and Uganda. Our objectives were (1) to determine the key variables to be included in a cardiac surgery needs assessment tool and (2) to highlight the current initiatives, challenges and opportunities, and future goals for cardiac surgery in these 3 countries.

Methods: We conducted in-depth interviews with stakeholders in each country as well as surveys of surgical facilities. We synthesized our findings using a health systems conceptual framework. Each program's current capacity was compared with a standardized definition of "adequate" surgical capacity. On the basis of these findings, we developed a formal needs assessment questionnaire for use in resource-constrained countries.

Results: Although each of these countries has adequate facilities and surgical expertise, they still lack key support staff and material resources. Training and mentorship programs are being built, and the sites participate in cardiovascular research. Yet a comprehensive, multidisciplinary approach-including palliative care and rehabilitation-is lacking, and patients in remote areas are not being served. These observations allowed us to define the variables in our needs assessment tool.

Conclusions: Our study demonstrates the great potential that exists to expand cardiac surgery in Africa and highlights some of the major resource bottlenecks that may hinder the scale-up of surgical programs. Our needs assessment questionnaire will assist ministries of health in building sustainable cardiac surgery programs using innovative Afro-centric solutions. (J Thorac Cardiovasc Surg 2019;158:1384-93)

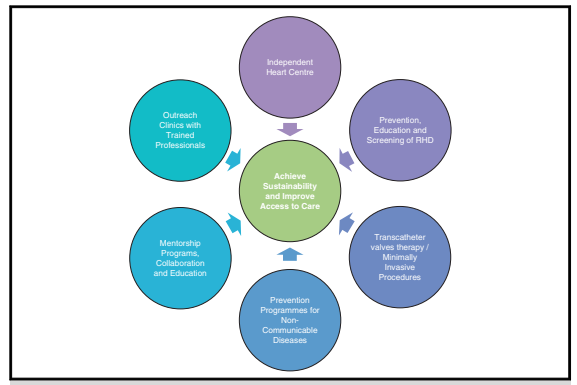

Future directions to achieve sustainability and to improve patients' access to care.

\section{Central Message}

Our study demonstrates the great potential that exists to expand cardiac surgery in Africa and highlights some of the major resource bottlenecks that may hinder the scale-up of surgical programs.

\section{Perspective}

Few African countries have the resources to provide optimal cardiac surgery care. This article explored needs at cardiac surgery centers in Namibia, Zambia, and Uganda. We determined the key variables to be included in a cardiac surgery needs assessment tool and highlighted the current initiatives, challenges and opportunities, and future goals for cardiac surgery in these countries.

See Commentaries on pages 1394 and 1397.
From the a Division of Cardiac Surgery, Université de Montréal, Department of Cardiac Surgery-Montreal University Hospital Centre (CHUM), Montreal, Canada; ${ }^{\mathrm{b}}$ Department of Medicine, University of Cape Town, Cape Town, South Africa; ${ }^{\mathrm{c}}$ Division of General Internal Medicine, University of Washington, Cape Town, ${ }^{\mathrm{d}}$ Chris Barnard Division of Cardiothoracic Surgery, University of Cape Town, Cape Town, Africa; ${ }^{e}$ Department of Cardiology, Windhoek Central Hospital, Windhoek, Namibia; ${ }^{\mathrm{f}}$ Department of Surgery, The University Teaching Hospital, Lusaka, Zambia; ${ }^{\mathrm{g}}$ Department of Cardiothoracic Surgery, Uganda Heart Institute, Kampala, Uganda; ${ }^{\mathrm{h}}$ Department of Cardiothoracic Surgery, MedStar University of Washington, Washington, DC; and ${ }^{\mathrm{i} D i v i s i o n}$ of Paediatric Cardiology, Department of Paediatrics, Red Cross War Memorial Children's Hospital, Faculty 20 of Health Sciences, Cape Town, South Africa.

D.A.W. and L.Z. are funded by Medtronic Foundation to support the work of RhEACH and RHDAction. L.Z. also receives funding from the Medical Research Council of South Africa and the National Research Foundation of South Africa.
Ethics approval and consent to participate: Participants provided a written consent before the interview. No patients were included in this study, only doctors and health allied professionals.

Co-contributors: Henning du Toit, Jones Nghaamwa, Simon Beshir, Fenny Shidhika, Mashaka Mwandileya, Evans Mulendele, John Musuku, Emmy S. Okello, Tom P. Mwambu, John Omagino, Peter Lwabi, and Wilson B. Nyakoojo provided input in the design of the assessment tools, participated in interviews, and provided key information in the acquisition of data.

Received for publication Sept 9, 2018; revisions received Dec 29, 2018; accepted for publication Jan 3, 2019; available ahead of print Feb 25, 2019.

Address for reprints: Jessica Forcillo, MD, MSc, MPH, FRCSC, 1051 rue Sanguinet, Montréal, Québec, Canada, H2X 3E4 (E-mail: jessica.forcillo@umontreal.ca). $0022-5223 / \$ 36.00$

Copyright (C) 2019 by The American Association for Thoracic Surgery

https://doi.org/10.1016/j.jtcvs.2019.01.054 

Abbreviations and Acronyms
CHD $=$ congenital heart disease
CVD $=$ cardiovascular disease
$\mathrm{NCD}=$ noncommunicable disease
RHD $=$ rheumatic heart disease
WHO $=$ World Health Organization

\section{Scanning this QR code will \\ take you to the article title page to access supplementary information.}

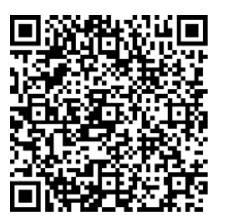

Few African countries have the resources to provide cardiac surgery care to their populations. In 2014, Yankah and colleagues ${ }^{1}$ described 22 cardiac surgery centers in subSaharan Africa. In those centers, 57 surgeons performed 1.6 open heart operations per million inhabitants. ${ }^{1}$ Likewise, in North America there is 1 cardiac surgical center for every 120,000 inhabitants, whereas in Africa, there is only 1 center for every 33 million inhabitants. ${ }^{1}$

Lack of access to cardiac surgery in African countries is an urgent problem that addresses a significant proportion of the total burden of noncommunicable diseases (NCDs). Although rates of degenerative cardiovascular diseases (CVDs) such as ischemic heart disease are increasing, ${ }^{2}$ morbidity and mortality from structural conditions such as congenital heart disease (CHD) and rheumatic heart disease (RHD) remain higher than in the rest of the world.

In addition to signing resolutions on NCD and CVD control, ${ }^{4}$ African heads of state recently endorsed a resolution to end RHD in Africa, and a key aspect of this resolution was an explicit call to scale-up cardiac surgical capacity across the continent. ${ }^{5}$

To do so, each Ministry of Health will need to develop a long-term plan that builds on existing resources using focused investments-particularly in the areas of infrastructure and human resources-in a sustainable manner. To this end and in accordance with the recent resolution mentioned previously, the present report centers on the development of a needs assessment questionnaire that can be used by public health specialists and decision makers to plan the expansion of cardiac surgery in their countries. This is the first questionnaire designed to assess cardiac surgery needs in Africa. To inform and test the design of our tool, we explored needs around cardiac surgery in 3 African countries with single-center surgical programs: Namibia, Zambia, and Uganda. The primary objective of this study was to gather data on the variables required for a cardiac surgery needs assessment questionnaire in the African context. In addition, we analyzed data from these 3 countries to compare and contrast current initiatives, challenges, and opportunities, and future goals around cardiac surgery. We conclude by discussing possible solutions to improve patient access to care and sustainability of cardiac surgery programs in Africa.

\section{MATERIALS AND METHODS Overview}

This was an exploratory study that implemented 2 different research techniques-in-depth interviews and structured questionnaires-to address our primary and secondary objectives. We collected data during September and October 2016 in Namibia, Zambia, and Uganda, where cardiac surgery services were present in each of the capital cities. These 3 countries were selected on the basis of preexisting collaborations with their cardiology/cardiac surgery centers as part of the Global Rheumatic Heart Disease Registry (REMEDY). ${ }^{6}$ This was a pilot project performed in middle-income countries of sub-Saharan Africa to test our questionnaire and further expand its use as a second phase of this project to the entire sub-Saharan Africa.

\section{Conceptual Framework}

To comprehensively assess current capacity for performing cardiac surgery, we developed a 5-block conceptual framework (Figure 1) that was modified from the World Health Organization (WHO) Health Systems Framework. ${ }^{7}$ Data were collected, organized, and analyzed with reference to our conceptual model.

\section{In-Depth Interviews}

In each country, we first convened a group of stakeholders with an indepth understanding of cardiac surgery provision from a range of (predominately clinical) perspectives. Participants were identified using a prespecified list of the most relevant categories of stakeholders, including ministers of health, senior medical superintendents, cardiac surgeons (adult and pediatric), cardiologists (adult and pediatric), interventional cardiologists, perfusionists, nurses, and anesthesiologists in each of those 3 countries. Participants were recruited using a snowball sampling approach: In each country, we identified an initial contact (REMEDY study collaborator) who then referred us to other relevant stakeholders, who then referred to other stakeholders until broad, multidisciplinary representation was achieved. We used a semistructured discussion guide (Online Data Supplement 1) to facilitate the conversations. Discussions focused on current access to and provision of surgical services, including challenges, potential solutions, and future plans for cardiac surgery. Each interview lasted between 1 and 2 hours. The interviews were performed individually and conducted in English, audio-recorded, and transcribed. The interviews were all administered by the first author of this article (J.F.).

\section{Facility Questionnaire}

We complemented the interviews with on-site assessment of these centers to quantify resources and understand the contexts in which these surgical centers were situated. Data were collected using a structured survey questionnaire (Online Data Supplement 2). ${ }^{8}$

\section{Sources of Statistical Data}

To provide context for our work, we consulted reports on general health and economic indicators from the World Bank,,${ }^{9}$ WHO, ${ }^{10}$ United Nations Children's Fund, ${ }^{11}$ and the Global Burden of Disease 2015 Study. ${ }^{12}$ In some cases, statistics were also obtained from local governments. 


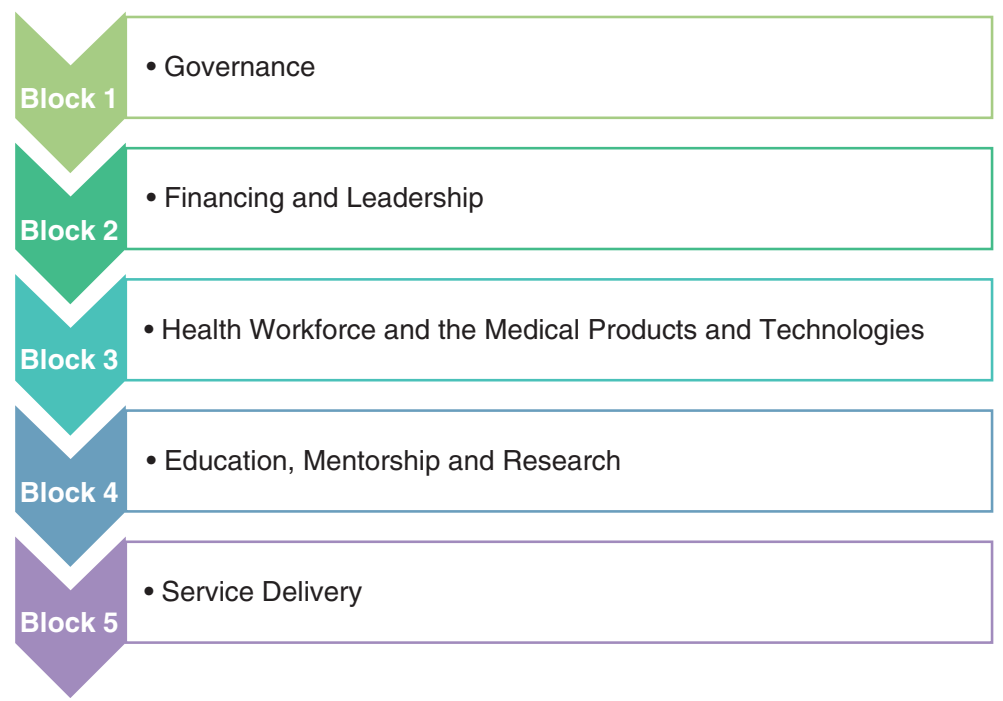

FIGURE 1. Cardiac surgery program: a system framework to comprehensively assess current capacity for performing cardiac surgery.

\section{Data Analysis}

For the in-depth interviews, we used thematic analysis to identify the most important topics that emerged from the transcript of each discussion. We grouped topics into categories following the conceptual framework described (Figure 1), noting barriers and facilitators separately. We then assessed which aspects of each theme were similar or different across the 3 countries.

We analyzed the facility questionnaires with reference to "an ideal" "minimum cardiac surgical standard" case appropriate to limitedresource countries (Table 1). This list was created after a group discussion with African and North American cardiac surgeons and cardiologists after performing a literature review, but also from surgeons' personal expertise and the commonalities of what countries aspired their cardiac surgery program to be in the future. Considerations were also taken about the kind of procedures that were prioritized in those countries, which are mainly valvular heart diseases, and the list of materials that were graded was chosen accordingly. Previous estimates have suggested 1 pediatric cardiologist per 500,000 population and 1 cardiac surgeon per 800,000 . Our estimates are far more conservative, taking into consideration the desperate lack of qualified staff in Africa. ${ }^{14}$ It implies that numbers even in the United States are inadequate, but then even more so in Africa, with millions of underserved people needing surgery.

We graded each facility's current capacity across the 33 human and material resources listed in the reference case. Current levels of each of the 33 resource categories were classified as inadequate, marginal, or adequate and were visualized as a heat map: red (inadequate), yellow (marginal), and green (adequate), respectively. A more detailed quantitative list of the specific material and human resources identified in each facility and the rationale for each color grading is included in Online Data Supplement 3.

\section{Development of the Cardiac Surgery Needs Assessment Tool}

By synthesizing these data, we identified shared similarities, challenges, and opportunities across each setting that provided a sense of the general issues with cardiac surgery in African settings. We adapted our original data-collection instruments (interview guide and structured questionnaire) into a formal cardiac surgery needs assessment tool. The tool was vetted by stakeholders in the 3 countries and the members of our research team.

\section{Ethical Considerations}

The ethical committees of each of 3 surgical centers approved the research protocol. Notably, for this study we did not seek to obtain data on efficiency, health worker performance indicators, or clinical outcomes. These issues would need to be addressed in a formal needs assessment with specific ethical approval to obtain patient-level data.

\section{RESULTS}

Country context and history of surgical programs are shown in Table 2.

In Namibia, the creation of the public and private cardiac centers occurred at the invitation of the Minister of Health in 2007 on the initiative of a cardiac surgeon and a pediatric cardiologist. Surgery began in the Windhoek Central Hospital in October 2010. In parallel, the private Namibian Heart Centre was opened at the Roman Catholic Hospital in 2011. In Zambia, cardiac surgery is performed at the Lusaka University Teaching Hospital since 2014, which is the national referral hospital. In Uganda, a cardiac surgery program was begun in 1968 with government support, but in 1971 the program stalled because of political instability and a shift in the focus of the Ministry of Health and reopened in 1988.

\section{Governance}

The main priorities of each of the ministries of health are communicable diseases control, maternal and child health, universal access to healthcare, and increasing human resources for health. However, because of the increase in the prevalence of NCDs, each country is starting to implement CVD prevention efforts. Cardiac surgery is not listed as a major priority in any official policy documents in any of the 3 countries. The exception is the Uganda Heart Institute, which signed a National Act in September 2016 that gave them full autonomy, perpetuity, and a national mandate. 
TABLE 1. Minimum surgical standard defined to perform cardiac surgery in country with fewer resources

This definition was created on the basis of basic needs to be able to perform surgical procedures for endemic CVDs in those countries that are mainly congenital and rheumatic valvular heart diseases.

1. The institution needs to have at least 1 dedicated cardiac operating room.

2. The institution needs to have at least 1 operational catheterization laboratory.

3. The cardiac surgery department should have a leader who advocates for the cardiac surgery service.

4. The cardiac surgery program needs to have governmental support.

5. To stay relevant to cardiac surgery practice, a surgeon needs to perform a minimum of 100-125 cases per year. ${ }^{13}$

6. At least 2 cardiac surgeons need to be part of the team.

7. At least 1 cardiac surgeon needs to be trained in basic congenital cardiac surgery (ASD, VSD, PDA, TOF, and coarctation)

8. All surgeons should be trained to perform ICU care.

9. The surgeons need to be fully competent to performed any valvular repair or replacement.

10. A strong referral system with at least 2 cardiologists is necessary.

11. At least 1 cardiologist formerly trained in echocardiographic imaging skills.

12. At least 1 pediatric cardiologist needs to be part of the team.

13. At least 1 pediatric cardiologist should be able to perform diagnostic catheterization procedures.

14. At least 1 cardiac anesthesiologist needs to be part of the team.

15. At least 1 intensivist trained in postcardiac surgical care needs to be part of the team.

16. At least 2 perfusionists need to be part of the team.

17. At least 1 cardiac technician* should be part of the team.

18. At least 6 formally trained ICU nurses should be part of the team.

19. At least 2 scrub nurses should be part of the team.

20. The material should include at least 1 functional cardiopulmonary bypass pump.

21. The institution should have all the material necessary to perform any valvular repair or replacement.

22. Easy access to intravenous inotropes and vasopressors, such as epinephrine, norepinephrine, vasopressin, milrinone, and dobutamine.

23. Easy access to blood products.

24. Easy access to cardiac medications, antiplatelets, and anticoagulants.

25. Material should include at least 3 respiratory ventilators.

26. Material should include at least 2 transthoracic echo probes and at least 1 transesophageal echo probe.

27. At least 3 cardiac ICU beds should be available.

28. The institution should have an INR clinic.

29. The institution should have access to 24 -h laboratory facilities and to a sterilization unit.

30. A transportation system and referral system should be in place for patients in remote areas of the country.

31. Collaboration, mentorship, and educational programs should exist with other countries.

32. The institution should have a database system.

33. A good follow-up system in-hospital and on the field should be implemented.

$C V D$, Cardiovascular disease; $A S D$, atrial septal defect; $V S D$, ventricular septal defect; $P D A$, patent ductus arteriosus; TOF, tetralogy of Fallot; ICU, intensive care unit; INR, international normalized ratio. *A cardiac technician in Africa performs the echocardiography and can also be at the console in the catheter laboratory.

\section{Financing and Leadership}

Public finance of these cardiac surgery programs is limited: Each government has invested substantially in the cardiac surgery centers, but resources have not been earmarked for maintenance and future program development. The governments of all 3 countries have instituted a fixed co-payment fee for public sector care, including cardiac surgery care. However, less than $30 \%$ of the population can afford this co-payment. The governments will pay for access to cardiac surgery for individuals who do not have the capacity to pay. Administrative capacity appears to be the biggest obstacle to expanding surgical care.

\section{Health Workforce, Medical Products, and Technologies}

The lack of human resources at all levels of care is a common issue in all 3 countries. Retention of healthcare workers is challenging because of high clinical demands and low salaries. As a result, staff sent to train abroad are generally contracted to return for a predetermined period, although this requirement has not fully addressed the workforce gap. Investment in new technologies is difficult. Procurement issues remain despite government support. The specific human and material resources are shown in Online Data Supplement 3.

\section{Education, Mentorship, and Research}

All the cardiac surgeons and cardiologists in these institutions have been trained abroad (South Africa, India, Canada, United States, United Kingdom, Uzbekistan, and Russia). They all returned to their countries with the same goal: to build a program for a population who is in real need of cardiac care. They are all involved in local training, but they do not have dedicated registrars/fellows in cardiac 
TABLE 2. Country context

\begin{tabular}{|c|c|c|c|}
\hline & Namibia & Zambia & Uganda \\
\hline Total population $^{7}$ & $2,459,000$ & $16,212,000$ & $39,032,000$ \\
\hline Life expectancy $\mathrm{M} / \mathrm{F}^{7}$ & $63 / 68$ & $59 / 65$ & $60 / 64$ \\
\hline World Bank income groups ${ }^{9}$ & High-middle & Lower-middle & Lower-middle \\
\hline Gross Domestic Product per capita (US\$) ${ }^{9}$ & 4696 & 1308 & 676 \\
\hline Gini coefficient $^{9}$ & 61 & 56 & 41 \\
\hline Gross National Income per capita (2016 US\$) ${ }^{9}$ & 5210 & 1500 & 670 \\
\hline Total expenditure on health per capita (2016 US\$) ${ }^{10}$ & $\$ 499$ & $\$ 86$ & $\$ 52$ \\
\hline $\begin{array}{l}\text { Proportion of total health expenditure paid by } \\
\text { government }(\%)^{10}\end{array}$ & 60 & 55 & 25 \\
\hline $\begin{array}{l}\text { The } 5 \text { most common overall causes of death in all } \\
\text { age groups }{ }^{12}\end{array}$ & $\begin{array}{l}\text { 1. HIV/AIDS } \\
\text { 2. Tuberculosis among } \\
\text { people with HIV } \\
\text { 3. LRTI } \\
\text { 4. IHD } \\
\text { 5. Tuberculosis }\end{array}$ & $\begin{array}{l}\text { 1. HIV/AIDS } \\
\text { 2. LRTI } \\
\text { 3. Diarrheal diseases } \\
\text { 4. IHD } \\
\text { 5. Malaria }\end{array}$ & $\begin{array}{l}\text { 1. HIV/AIDS } \\
\text { 2. LRTI } \\
\text { 3. Malaria } \\
\text { 4. Diarrheal diseases } \\
\text { 5. Neonatal encephalopathy }\end{array}$ \\
\hline $\begin{array}{l}\text { The } 3 \text { most common causes of cardiovascular death } \\
\text { in children }(5-14 \mathrm{y})^{12}\end{array}$ & $\begin{array}{l}\text { 1. CHD } \\
\text { 2. RHD } \\
\text { 3. Cardiomyopathies }\end{array}$ & $\begin{array}{l}\text { 1. CHD } \\
\text { 2. Other cardiovascular } \\
\text { 3. RHD }\end{array}$ & $\begin{array}{l}\text { 1. CHD } \\
\text { 2. Other cardiovascular } \\
\text { 3. RHD }\end{array}$ \\
\hline $\begin{array}{l}\text { The most common causes of cardiovascular death } \\
\text { in adults }\end{array}$ & $\begin{array}{l}\text { 1. IHD } \\
\text { 2. Cardiomyopathies } \\
\text { 3. Hypertensive heart } \\
\text { disease }\end{array}$ & $\begin{array}{l}\text { 1. IHD } \\
\text { 2. Other cardiovascular } \\
\text { 3. Hypertensive heart disease }\end{array}$ & $\begin{array}{l}\text { 1. IHD } \\
\text { 2. Other cardiovascular } \\
\text { 3. Hypertensive heart disease }\end{array}$ \\
\hline Maternal mortality ratio per 100,000 live births ${ }^{11}$ & 450 & 480 & 440 \\
\hline Infant mortality per 1000 live births ${ }^{11}$ & 30 & 56 & 45 \\
\hline Under 5 mortality rate per 1000 live births ${ }^{11}$ & 42 & 89 & 69 \\
\hline Age of cardiac surgery program (y) & 9 & 2 & 28 \\
\hline
\end{tabular}

surgery to formally train them. No postgraduate training programs have been approved locally.

Local research is limited but growing in each academic center. The Namibians promote continuous mentorship with in-service specialists leading the respective service divisions. A strong research unit is developing in Pediatric Cardiology, which has collaborated and published through REMEDY, ${ }^{6,15}$ RHDGen (on the genetics of RHD), and adult CHD. ${ }^{16,17}$ Consistent with their human resource model, Zambia collaborates with mentoring physicians coming from Italy once per year as part of the "Bambini mission" that operates on more complex congenital pediatric cases and provides further training to local surgeons. Uganda is the only country of the 3 with a postgraduate training program for their cardiology trainees, although they do not yet have a training program for cardiac surgeons. Uganda has a partnership with Children's National Medical Centre in Washington, DC, which since its inception in 2007 has significantly expanded the number of congenital cases performed. The
Uganda Heart Institute group uses a telemedicine approach to training and collaboration. ${ }^{18}$

\section{Service Delivery}

In all these institutions, surgeons perform approximately 2 to 3 cases per week on average. The demands for cardiac surgery services exceed the supply, with 60 to 500 patients on the cardiac surgery waiting list in each country. Namibia and Zambia cannot perform complex congenital cases, which are sent abroad (eg, to India, the United States, or South Africa) and are paid for by government or charity organizations. In all 3 countries, cases are frequently canceled for reasons as diverse as power outages, water and sanitation issues, lack of blood products, lack of human resources, or lack of consumables (surgical materials and prostheses). The priorities are congenital and rheumatic valvular cases; most adults who need cardiac surgery (eg, for ischemic heart disease) never receive it. The recommended followup of local patients is generally good but is challenging for those patients who live in remote areas $(20 \%)$. 
Individuals living in the rural areas must make choices about spending their money on transportation for their follow-up appointment versus spending that money on food or other needs for their family. Therefore, the rate of loss to follow-up is more than $80 \%$ in patients living in the remote areas according to the local doctors interviewed. Unfortunately, late presentation and diagnosis are extremely common, and many patients only present at the "palliative" stage; however, no formal palliative care services are in place. In addition, none of the countries have a cardiac rehabilitation program. In those countries, the majority of the population live in the remote areas, and accessibility to healthcare services is a major challenge. Efforts to establish more outreach clinics that offer at least basic medical care are ongoing. "Flying doctor" service for patients who live in the remote areas exist, but the number of planes is limited. Staffing is a major issue, as is the absence of regional hospitals. Uganda is the only center that is able to operate on infants ( $>5 \mathrm{~kg}$ ) and can perform some of the more complex CHD cases.

\section{Summary of Current Cardiac Surgery Capacity}

Figure 2 illustrates each facility's current capacity to deliver cardiac surgery using a matrix of the 33 variables listed in the minimum surgical standard reference case (Figure 2). Generally, each country had adequate physical infrastructure and supply of specialist physicians and surgeons to perform surgery. However, the programs all suffer from inadequate supplies of surgical materials (prosthetic valves and related supplies).

\section{Cardiac Surgery Needs Assessment Tool}

On the basis of our results and the data-collection instruments used for this study, we developed a needs assessment tool divided into the following themes: (1) cardiac surgery facilities; (2) governance, administration, and leadership; (3) population access to care; (4) human resources; (5) physician training; (6) physicians' practice; (7) material resources; (8) disease prevention; and (9) service delivery (Online Data Supplement 4). The tool is a questionnaire that is anticipated to take 2 or 3 hours at most, depending on whether it is an "interview" or is self-administered. If time and resources permit, we recommend that the questionnaire be completed in consultation with those currently responsible for surgical care (ie, cardiac surgeon, cardiologist, and medical superintendent/program administrator). We also recommend on-site facility assessment if the questionnaire is being used by a ministry of health rather than self-administered by local practitioners.

\section{DISCUSSION}

Through stakeholder interviews and facility surveys, we have identified a lack of capacity to deliver cardiac surgery in Namibia, Zambia, and Uganda at an acceptable level of quality. Although we found gaps throughout all aspects of the health system, the lack of sufficient human resources to provide optimal perioperative care remains the major barrier to meeting current demand. None of the 3 centers currently have the resources to develop a "comprehensive" program including rehabilitation and palliative care. At the same time, each country highlighted unique strengths and innovations that might also be applicable in other African countries. From this work, we have developed a needs assessment tool that can be used to identify gaps in care and develop and evaluate interventions and program improvements that sustainably increase access to surgical care. However, we stress that in a continent still grappling with infectious diseases and diseases of poverty, we are not advocating to prioritize cardiac surgery over these other important issues, but rather to integrate cardiac surgery and advanced cardiac interventions such as catheterization expertise into regional services. The call for global surgery has stressed surgical services as key elements of a properly functioning healthcare system and a prerequisite for universal health coverage. ${ }^{19}$

We have identified clear concerns, such as the loss to follow-up in rural settings, a common theme in all 3 countries, which requires innovative approaches to the continuum of care. These could be addressed by community health workers, telemedicine links, and nurse practitioner-led clinics to lower the rate of lost care. African countries also face significant additional challenges, which include lack of equipment and physical beds. These challenges result in far less surgery per week than should be the case per surgeon, despite demand. Global awareness of these challenges may assist units to advocating for improvement in infrastructure.

\section{Advocacy at the Governmental Level}

Our interaction with ministries of health suggests that there is realization of the need for prioritizing NCDs. Governments are also starting to focus on preventing disease through inexpensive population-based policies; however, the lack of human and material resources for treatment of existing cases (especially surgical ones) is a problem in light of the ethical imperative of treating patients who currently need care. Sustainable public finance of cardiac surgery services remains a major challenge, and in the short term, this will need to be addressed by increased donor aid through public-private partnerships. In these 3 countries, governments have already taken some steps to improve access to tertiary care (eg, transportation support for patients living in the remote areas, telemedicine); however, these are not sufficient to meet current demand. Further, it is unlikely that cardiac surgical procedures themselves can be decentralized beyond the capital cities in the short term, so governments should be encouraged to continue investing 


\begin{tabular}{|c|c|c|c|}
\hline Namibia (Public) & Namibia (Private) & Zambia & Uganda \\
\hline Operating room & Operating room & Operating room & Operating room \\
\hline CPB & CBP & CBP & CBP \\
\hline $\begin{array}{l}\text { Access to surgical } \\
\text { instruments }\end{array}$ & $\begin{array}{l}\text { Access to surgical } \\
\text { instruments }\end{array}$ & $\begin{array}{l}\text { Access to surgical } \\
\text { instruments }\end{array}$ & $\begin{array}{l}\text { Access to surgical } \\
\text { instruments }\end{array}$ \\
\hline Access to prosthetic valves & Access to prosthetic valves & Access to prosthetic valves & Access to prosthetic valves \\
\hline $\begin{array}{l}\text { Access to autologous } \\
\text { pericardial patches and } \\
\text { dacron tubes }\end{array}$ & $\begin{array}{l}\text { Access to autologous } \\
\text { pericardial patches and } \\
\text { dacron tubes }\end{array}$ & $\begin{array}{l}\text { Access to autologous } \\
\text { pericardial patches and } \\
\text { dacron tubes }\end{array}$ & $\begin{array}{l}\text { Access to autologous } \\
\text { pericardial patches and } \\
\text { dacron tubes }\end{array}$ \\
\hline $\begin{array}{l}\text { Access to IV inotropes and } \\
\text { vasopressors }\end{array}$ & $\begin{array}{l}\text { Access to IV inotropes and } \\
\text { vasopressors }\end{array}$ & $\begin{array}{l}\text { Access to IV inotropes and } \\
\text { vasopressors }\end{array}$ & $\begin{array}{l}\text { Access to IV inotropes and } \\
\text { vasopressors }\end{array}$ \\
\hline Access to blood products & Access to blood products & Access to blood products & Access to blood products \\
\hline Respiratory ventilators & Respiratory ventilators & Respiratory ventilators & Respiratory ventilators \\
\hline TTE and TEE & TTE and TEE & TTE and TEE & TTE and TEE \\
\hline ICU beds & ICU beds & ICU beds & ICU beds \\
\hline Unit beds & Unit beds & Unit beds & Unit beds \\
\hline $\begin{array}{l}\text { 24-hour laboratory } \\
\text { facilities and sterilization } \\
\text { unit }\end{array}$ & $\begin{array}{l}\text { 24-hour laboratory } \\
\text { facilities and sterilization } \\
\text { unit }\end{array}$ & $\begin{array}{l}\text { 24-hour laboratory } \\
\text { facilities and sterilization } \\
\text { unit }\end{array}$ & $\begin{array}{l}\text { 24-hour laboratory } \\
\text { facilities and sterilization } \\
\text { unit }\end{array}$ \\
\hline $\begin{array}{l}\text { Collaboration/mentorship } \\
\text { and educational programs }\end{array}$ & $\begin{array}{l}\text { Collaboration/mentorship } \\
\text { and educational programs }\end{array}$ & $\begin{array}{l}\text { Collaboration/mentorship } \\
\text { and educational programs }\end{array}$ & $\begin{array}{l}\text { Collaboration/mentorship } \\
\text { and educational programs }\end{array}$ \\
\hline Catheterization lab & Catheterization lab & Catheterization lab & Catheterization lab \\
\hline $\begin{array}{l}\text { Access to cardiac } \\
\text { medication, antiplatelets } \\
\text { and anticoagulants }\end{array}$ & $\begin{array}{l}\text { Access to cardiac } \\
\text { medication, antiplatelets } \\
\text { and anticoagulants }\end{array}$ & $\begin{array}{l}\text { Access to cardiac } \\
\text { medication, antiplatelets } \\
\text { and anticoagulants }\end{array}$ & $\begin{array}{l}\text { Access to cardiac } \\
\text { medication, antiplatelets } \\
\text { and anticoagulants }\end{array}$ \\
\hline $\begin{array}{l}\text { Coumadin clinic, INR point } \\
\text { of care }\end{array}$ & $\begin{array}{l}\text { Coumadin clinic, INR point } \\
\text { of care }\end{array}$ & $\begin{array}{l}\text { Coumadin clinic, INR point } \\
\text { of care }\end{array}$ & $\begin{array}{l}\text { Coumadin clinic, INR point } \\
\text { of care }\end{array}$ \\
\hline Database & Database & Database & Database \\
\hline Follow-up system & Follow-up system & Follow-up system & Follow-up system \\
\hline $\begin{array}{l}\text { Cardiac rehabilitation } \\
\text { services }\end{array}$ & $\begin{array}{l}\text { Cardiac rehabilitation } \\
\text { services }\end{array}$ & $\begin{array}{l}\text { Cardiac rehabilitation } \\
\text { services }\end{array}$ & $\begin{array}{l}\text { Cardiac rehabilitation } \\
\text { services }\end{array}$ \\
\hline Palliative care services & Palliative care services & Palliative care services & Palliative care services \\
\hline Transportation system & Transportation system & Transportation system & Transportation system \\
\hline Cardiac surgeons & Cardiac surgeons & Cardiac surgeons & Cardiac surgeons \\
\hline Adult cardiologists & Adult cardiologists & Adult cardiologists & Adult cardiologists \\
\hline Paediatric cardiologists & Paediatric cardiologists & Paediatric cardiologists & Paediatric cardiologists \\
\hline Intensivists & Intensivists & Intensivists & Intensivists \\
\hline Cardiac anaesthesiologists & Cardiac anaesthesiologists & Cardiac anaesthesiologists & Cardiac anaesthesiologists \\
\hline Perfusionists & Perfusionists & Perfusionists & Perfusionists \\
\hline Cardiac surgery nurses & Cardiac surgery nurses & Cardiac surgery nurses & Cardiac surgery nurses \\
\hline Cardiology technicians & Cardiology technicians & Cardiology technicians & Cardiology technicians \\
\hline
\end{tabular}

FIGURE 2. Heat maps of surgical, medical, and human resource constraints in the 3 study countries. $C P B$, Cardiopulmonary bypass; $C B P$, cardiopulmonary bypass; $I V$, intravenous; $T T E$, transthoracic echocardiography; TEE, transesophageal echocardiography; ICU, intensive care unit; $I N R$, international normalized unit. 
in "outreach clinics" for specialist physicians and surgeons.

African countries all face significant competing health challenges. The huge increase in the incidence of CVD in Africa has resulted in a call for management of these conditions and building capacity for treating these at the tertiary level. A comment at the WHO conference in 2005 on the prevention of chronic disease by Nigeria's President $\mathrm{O}$. Obasanjo was instructive. He said, "We cannot afford to say, we must tackle the other diseases first-HIV/AIDS, malaria, tuberculosis - then we will deal with chronic disease; if we wait even 10 years we will find that the problem is even larger and more expensive to address."

\section{Prevention of Rheumatic Heart Disease}

All 3 countries identified RHD prevention as a common goal. The recent REMEDY study of more than 3000 patients from African countries estimated a mortality rate of $17 \%$ over 24 months. Deaths were mostly among patients who had presented in heart failure, which illustrates that late presentation and diagnosis of RHD are the norm and that cardiac surgery itself cannot help all patients. ${ }^{20}$ Education about streptococcal group A infection and the importance of primary and secondary prevention is crucial to prevent and control RHD and to reduce the overall burden of surgical disease in the future. The CVD community could also become better advocates for improved antenatal care (including micronutrient supplementation) ${ }^{21}$ which might be helpful in reducing the incidence of CHD in the future.

\section{Mentorship Programs, Collaboration, and Education}

So-called "North-South" and "South-South" mentorship programs and collaborations appear to important mechanisms for meeting training needs in cardiac surgery. We identified South-South collaboration in Namibia and North-South collaboration in Zambia, whereas the Uganda Heart Institute took a mixed approach. Our analysis suggests that these collaborations have been successful at recruiting physicians and surgeons, but they have not fully addressed the need for other health professionals, such as intensivists, perfusionists, and specialized cardiac nurses. To address these gaps, a more comprehensive approach to cardiac surgery training will be required. More robust online learning and telemedicine support could complement hands-on learning; these methods appear to increase knowledge and confidence, for example, in basic echocardiography skills among nonexpert health workers. They would also reduce the human resource requirements for training staff. $^{22}$ Locally, regional hospital support and education of local physicians on cardiac surgery issues will be needed to strengthen early diagnosis and referral chains to prevent late presentation and avoidable mortality.

\section{A "Heart Center" as a First Step}

A privately managed Heart Center with services purchased by government through capitation could service both public and private sector patients. Cardiac surgery operates in a multidisciplinary environment where a team approach, working toward the same patient-centered goals, offers the best chance of service excellence. It would be up to the state to determine its budget to increase access to cardiac care for patients completely dependent on the state for healthcare. The "risk" of service management would be completely outsourced to the private sector. Government could concentrate on the further development of teaching program so that cardiac care in country is indigenous and sustainable. The Ghanaian-German model has demonstrated that the determining factor for the sustainability of a cardiac surgery program in sub-Saharan Africa is leadership rather than financing. ${ }^{23,24}$ Treating more patients locally is an important aim, because an operation costs US $\$ 5000$ to $\$ 7000$ in-country compared with US $\$ 20,000$ abroad. With the centralization of cardiac care, the volume of cases could increase and training programs might improve. However, this model has not been validated in the African context, and previous attempts at such a mixed model have had variable success. ${ }^{25,26}$

\section{Transcatheter Valves Replacement, Minimally Invasive Procedures, and New Technologies}

Transcatheter valvular therapies could be used as a minimally invasive alternative to address valvular pathologies caused by RHD. In Cape Town, Strait Access Technologies is currently designing a more affordable transcatheter valve to treat aortic insufficiency. Also, this procedure can be performed via a "minimalist" technique that results in shortened hospital stays and the need for fewer resources. ${ }^{27}$ It is noteworthy that transcatheter services assume adequately

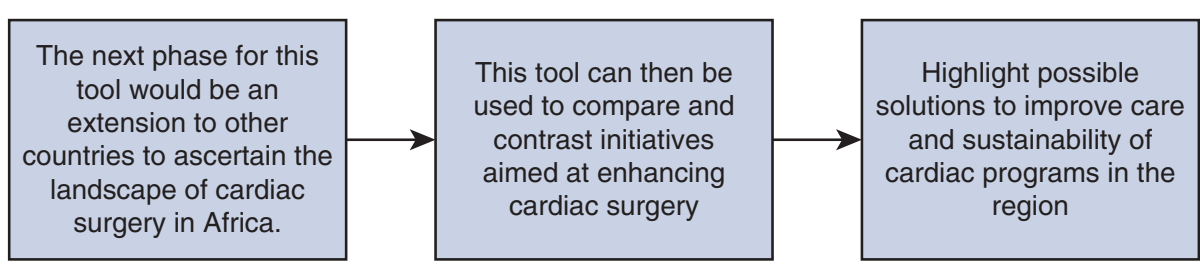

FIGURE 3. Summary of the plan of actions to improve delivery of cardiac surgical care in sub-Saharan Africa. 


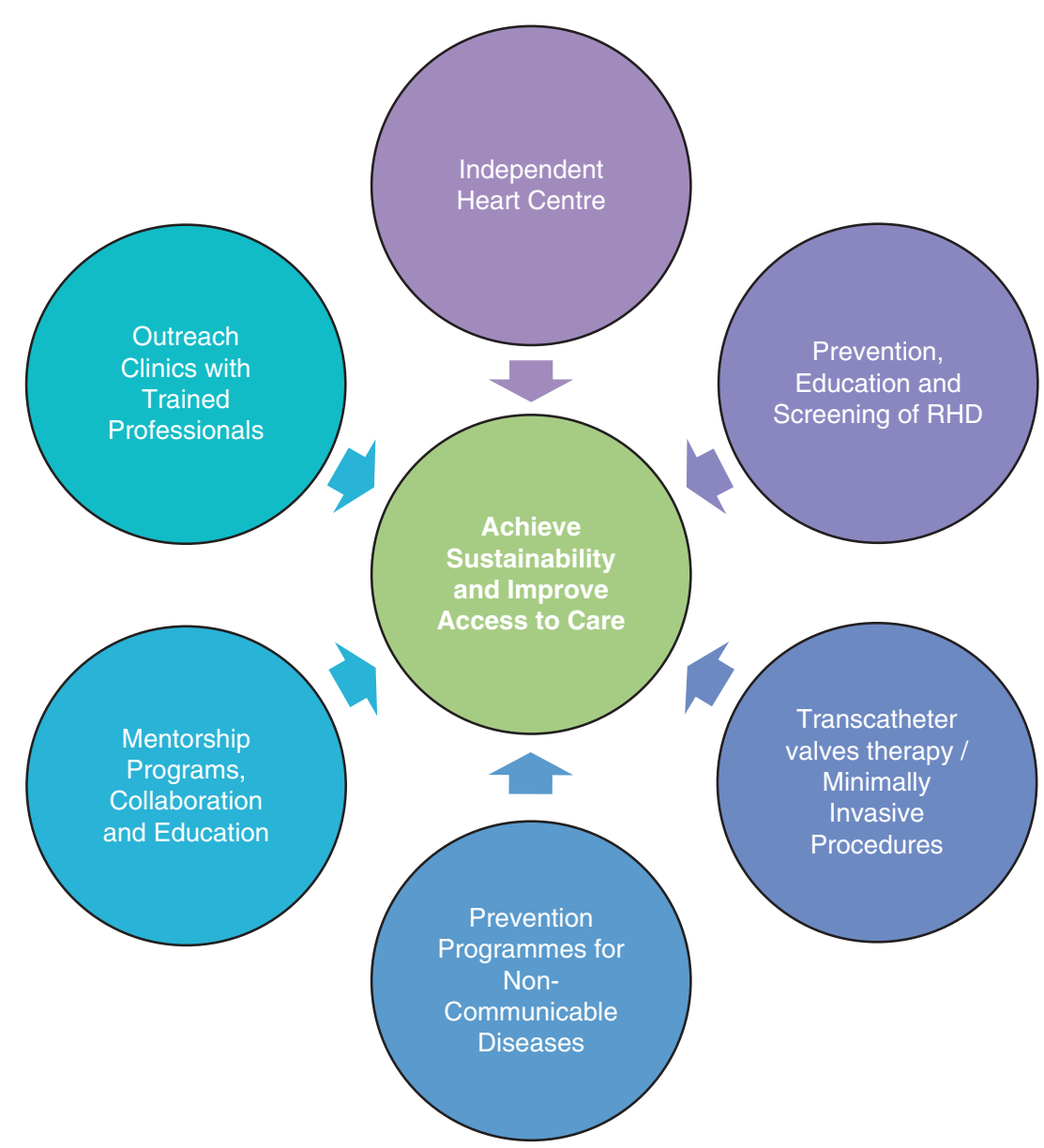

FIGURE 4. Future directions to achieve sustainability and to improve patients' access to cardiac surgery care. $R H D$, Rheumatic heart disease.

trained interventional cardiologists or surgeons, as well as a functioning catheterization laboratory. These limitations notwithstanding, we believe this is an exciting area for the future of cardiac surgery and should be a part of the longterm plan for building surgical capacity.

\section{Limitations and Future Directions}

The next phase for this tool would be an extension to other countries to ascertain the landscape of cardiac surgery in Africa. This tool can then be used to compare and contrast initiatives aimed at enhancing cardiac surgery and highlight possible solutions to improve care and sustainability of cardiac programs in the region (Figure 3). Our study was performed in 3 stable African countries, and our findings should not be extrapolated to fragile African states that have other challenges. Findings from broad, multicountry needs assessments can inform the direction for cardiac surgery across the continent, particularly with a view to addressing gaps and building regional capacity. ${ }^{1,3}$ They can also provide data for a more coherent health system response, provide further information about the amount of investment needed, and facilitate the development of cardiac surgery units. The vision for sustainable cardiac surgery in Africa needs a broad, multidisciplinary framework for every country (Figure 4) accompanied by a collaborative call for surgery such as the "The Cape Town Declaration." ${ }^{28}$ Finally, we emphasize that this is not a performance tool. This aspect would require a follow-on chart review and audit with additional ethics approval.

\section{CONCLUSIONS}

We have developed a needs assessment tool in conjunction with an exploration of cardiac surgery challenges and opportunities in 3 African countries. Our study demonstrates the great potential that exists to expand cardiac surgery in Africa and highlights some of the major resource bottlenecks that may hinder the scale-up of surgical programs. We plan to use this tool in a variety of other African countries to provide an updated look at the landscape of cardiac surgery on the continent. Our tool is a critical first step in improving the sustainability of cardiac surgery and improving patient access to care through innovative Afrocentric solutions. 


\section{Conflict of Interest Statement}

Authors have nothing to disclose with regard to commercial support.

\section{References}

1. Yankah C, Fynn-Thompson F, Antunes M, Edwin F, Yuko-Jowi C, Mendis S, et al. Cardiac surgery capacity in sub-Saharan Africa: quo vadis? Thorac Cardiovasc Surg. 2014;62:393-401.

2. Unger F. European survey on cardiac interventions: open-heart surgery, percutaneous transluminal coronary angioplasty and cardiac catheterization in 1993. A preliminary report by the institute for cardiac survey of the European academy of sciences and arts. Cardiovasc Surg. 1995;3:569-71.

3. Zuhlke L, Mirabel M, Marijon E. Congenital heart disease and rheumatic heart disease in Africa: recent advances and current priorities. Heart. 2013;99:1554-61.

4. World Health Organization (WHO). African Health Ministers adopt Brazzaville Declaration on Noncommunicable Diseases. 2011. Available at: http://www.afro. who.int/en/media-centre/pressreleases/item/2839-african-health-ministers-adoptbrazzaville-declaration-on-noncommunicable-diseases.html. Accessed November 25,2016 .

5. Watkins D, Zuhlke L, Engel M, Daniels R, Francis V, Shaboodien G, et al. Seven key actions to eradicate rheumatic heart disease in Africa: the Addis Ababa communique. Cardiovasc J Afr. 2016;27:1-5.

6. Zuhlke L, Engel ME, Karthikeyan G, Rangarajan S, Mackie P, Cupido B, et al. Characteristics, complications, and gaps in evidence-based interventions in rheumatic heart disease: the global rheumatic heart disease registry (the REMEDY study). Eur Heart J. 2015;36:1115-1122a.

7. World Health Organization. The WHO Health Systems Framework. 2016. Available at: http://www.wpro.who.int/health_services/health_systems_framework/ en/. Accessed June 10, 2016

8. Zuhlke LJ, Watkins DA, Perkins S, Wyber R, Mwangi J, Markbreiter J, et al. A comprehensive needs assessment tool for planning rheumatic heart disease control programs in limited resource settings. Glob Heart. 2017;12:25-31.

9. The World Bank. World Development Indicators. 2016. Available at: http://data. worldbank.org/indicator/NY.GNP.PCAP.CD. Accessed December 15, 2016.

10. World Health Organization. Data and Statistics. 2016. Available at: http://www. wpro.who.int/en/. Accessed December 15, 2016

11. UNICEF. UNICEF, statistics. 2013. Available at: http://www.unicef.org/ infobycountry/zambia_statistics.html. Accessed October 11, 2016.

12. Institute for Health Metrics and Evaluation. GBD Compare. 2013. Available at: http://vizhub.healthdata.org/gbd-compare/. Accessed November 25, 2016.

13. American College of Surgeons. Guidelines for standards in cardiac surgery. Bull Am Coll Surg. 1997;82(2).

14. Sliwa K. The heart of Africa: succeeding against the odds. Lancet. 2016;388: e28-36.
15. Zuhlke L, Karthikeyan G, Engel ME, Rangarajan S, Mackie P, Cupido-Katya Mauff B, et al. Clinical outcomes in 3343 children and adults with rheumatic heart disease from 14 low and middle income countries: 2-year follow-up of the global rheumatic heart disease registry (the REMEDY study). Circulation. 2016;134:1456-66

16. Shidhika FBA, Vosloo S, Hugo-Hamman C. Saving lost lives; The Namibian children's heart project. Cardiovasc J Afr. 2015;26:18.

17. Hewitson J, Zilla P. Children's heart disease in Sub-Saharan Africa: challenging the burden of disease. S Afr Heart. 2010;7:18-29.

18. Okello E, Beaton A, Mondo CK, Kruszka P, Kiwanuka N, Odoi-Adome R, et al. Rheumatic heart disease in Uganda: the association between MHC class II HLA DR alleles and disease: a case control study. BMC Cardiovasc Disord. 2014;14 28.

19. Meara JG, Greenberg SL. The Lancet commission on global surgery global surgery 2030: evidence and solutions for achieving health, welfare and economic development. Surgery. 2015;157:834-5.

20. Karthikeyan G, Zuhlke L, Engel M, Rangarajan S, Yusuf S, Teo K, et al, Rationale and design of a global rheumatic heart disease registry: the REMEDY study Am Heart J. 2012;163:535-540 e1.

21. World Health Organization (WHO). Daily iron and folic acid supplementation during pregnancy. 2016. Available at: http://www.who.int/elena/titles/daily_ iron_pregnancy/en/. Accessed November 25, 2016.

22. Engelman D, Okello E, Beaton A, Selnow G, Remenyi B, Watson C, et al. Evaluation of computer-based training for health workers in echocardiography for rheumatic heart disease. Glob Heart. 2017;12:17-23.e8.

23. Edwin F, Tettey M, Aniteye E, Tamatey M, Sereboe L, Entsua-Mensah K, et al The development of cardiac surgery in West Africa-the case of Ghana. Pan Afr Med J. 2011:9:15.

24. Turina MI. European Association for Cardio-Thoracic Surgery: carrying the torch. Eur J Cardiothorac Surg. 2002;22:857-63.

25. Buchanan E. Walter Sisulu paediatric cardiac centre opened by Nelson Mandela S Afr Med J. 2004;94:14.

26. Surgery TSCfC. The Regional Network. 2016. Available at: http://www salamcentre.emergency.it. Accessed December 15, 2016.

27. Jensen HA, Condado JF, Devireddy C, Binongo J, Leshnower BG, Babaliaros V, et al. Minimalist transcatheter aortic valve replacement: the new standard for surgeons and cardiologists using transfemoral access? J Thorac Cardiovasc Surg 2015;150:833-9.

28. Zilla P, Bolman RM, Yacoub MH, Beyersdorf F, Sliwa K, Zühlke L, et al. The Cape Town declaration on access to cardiac surgery in the developing world. $S$ Afr Med J. 2018;108:702-4.

Key Words: cardiac surgery, cardiac surgery programs, sustainability, South Africa, public health 